\title{
Inhibin- $\alpha$ subunit in normal and malignant human cervical tissue and cervical cancer cell lines
}

\author{
IOANNIS MYLONAS and DARIUS DIAN
}

First Department of Obstetrics and Gynaecology, Ludwig Maximilian University of Munich, D-80337 Munich, Germany

Received April 21, 2011; Accepted May 30, 2011

DOI: $10.3892 /$ or.2011.1379

\begin{abstract}
Inhibins are dimeric glycoproteins composed of an $\alpha$-subunit and one of two possible $\beta$-subunits ( $\beta A$ or $\beta B$ ), with substantial roles in human reproduction and in endocrineresponsive tumours. Four normal cervical tissue samples together with 10 specimens of well-differentiated squamous cervical cancer and adenocarcinoma of the cervix were immunohistochemically analysed for the expression of the inhibin- $\alpha$ subunit. Additionally, two cervical carcinoma cell lines (HeLa and CaSKi) were analysed with immunofluorescence and RT-PCR for the expression of the inhibin- $\alpha$ subunit. We demonstrated for the first time an immunolabelling of the inhibin- $\alpha$ subunit in normal and malignant cervical tissue, as well as cervical cancer cells. However, the immunoreactive reaction was albeit weak and mostly confined to mitotic cells in the analysed cervical tissues. Additionally, the expression pattern of this subunit was rather inconsistent. Therefore, the immunohistochemical evaluation of this subunit in cervical tissue cannot be used as a prognostic marker as suggested for endometrial cancer. However, since the expression of the inhibin- $\alpha$ subunit is minimal in HeLa cells as assessed by immunofluorescence and RT-PCR, the CaSKi cell line might be a better model for further functional experiments regarding cervical pathogenesis.
\end{abstract}

\section{Introduction}

Since the implementation of screening programs with the objective to prevent invasive cervical cancer by detecting its precursor cervical lesions, the incidence of this cancer has declined in the more developed countries. However, cervical cancer is still the second most common malignant disease among women worldwide with more than 500,000 new cancer cases every year, especially in less developed countries $(1,2)$.

Correspondence to: Dr Ioannis Mylonas, First Department of Obstetrics and Gynaecology, Ludwig Maximilian University of Munich, Maistrasse 11, D-80337 Munich, Germany

E-mail: ioannis.mylonas@med.uni-muenchen.de

Key words: cervical cancer, cervical cancer cell lines, immunohistochemistry, immunofluorescence, RT-PCR, inhibin- $\alpha$
Although several risk factors for the development of cervical cancer have been recognized, including HPV infection (3-6), the precise mechanism involved in carcinogenesis is still quite unclear and no effective tumour markers are available.

Inhibins and activins are secreted polypeptides, representing a subgroup of the TGF $\beta$ superfamily of growth and differentiation factors $(7,8)$. Inhibins are heterodimers that consist of an $\alpha$-subunit and one of two possible $\beta$-subunits $(\beta \mathrm{A}$ or $\beta \mathrm{B})$, resulting in the formation of either inhibin $A(\alpha-\beta A)$ or $B(\alpha-\beta B)$, respectively. In contrast, activins are homodimers of $\beta$-subunits linked by a disulphide bond $(7,8)$. Furthermore, two additional $\beta$-subunits have been identified in humans, $\beta C$ and $\beta E$ (7). Although these novel subunits are synthesised in a wide range of normal and malignant tissues (9-15), their precise function still remains unclear.

The inhibin subunits have been detected in female endocrine tumours, suggesting important roles in malignant cell transformation (16-20). However, one of the most intriguing functions of the inhibin- $\alpha$ subunit is its tumour-suppressor activity (19), which was first identified after functional deletion of the inhibin- $\alpha$ gene in mice (21). Inhibin- $\alpha$ knockout mice presented with gonadal stromal tumours, and even after these tumours were removed at an early age, these gonadectomised mice developed adrenal cortical sex steroidogenic tumours, demonstrating the tumour-suppressor function in the ovary and the adrenal gland (22).

We recently demonstrated the expression of the novel $\beta C$ (15) and $\beta E$-subunit (9) in cervical cancer and cervical cancer cell lines, suggesting a substantial function in cervical pathogenesis. Recently, both inhibin- $\beta A$ and $-\beta B$ subunits demonstrated a differential expression in cervical intraepithelial neoplasia (CIN) and squamous cancer, suggesting important roles in cervical carcinogenesis (23). Inhibin- $\beta$ A appears to be important during the progression of cervical intraepithelial neoplasia, while the inhibin- $\beta \mathrm{B}$ subunit may exert a substantial function during differentiation of cervical carcinomas (23). Additionally, we demonstrated a differential expression pattern of inhibin- $\beta A$ and $-\beta B$ subunits in normal and malignant glandular epithelial cells, including cervical adenocarcinomas (24). Although endocrine-related cancers express the inhibin- $\alpha$ subunit $(19,20,25)$, it is still unclear whether normal or cancerous cervical epithelial cells as well as cervical cancer cell lines can synthesise this subunit. Therefore, the aim of this study was to analyse the expression of the $\alpha$-subunit in normal and pathological cervical tissue as well as cervical carcinoma cell lines. 


\section{Materials and methods}

Tissue samples. Samples of uterine cervical tissue were obtained from 4 premenopausal, non-pregnant patients undergoing hysterectomy for uterine leiomyomata. Additionally, 10 specimens of well-differentiated (G1) squamous cervical cancer and 10 tissue samples of well-differentiated (G1) adenocarcinoma of the cervix of a well-characterized group $(9,15,23,24)$ were obtained from the pathological archives of the First Department of Obstetrics and Gynaecology, Ludwig Maximilian University of Munich.

Immunohistochemistry. Immunohistochemistry was performed using a combination of pressure cooker heating and the standard streptavidin-biotin-peroxidase complex by using the mouse-IgG Vectastain Elite ABC kit (Vector Laboratories, Burlingame, CA, USA) as previously described $(16,25-27)$ with slightly modifications.

Briefly, paraffin-fixed tissue sections were dewaxed using xylol for $15 \mathrm{~min}$ and rehydrated in $100 \%$ of ethanol twice. Endogenous peroxidase activity was quenched by immersion in 3\% hydrogen peroxide (Merck, Darmstadt, Germany) in methanol for $20 \mathrm{~min}$. After washing, slides were subjected to antigen retrieval for $5 \mathrm{~min}$ in a pressure cooker using sodium citrate buffer ( $\mathrm{pH}$ 6.0), containing $0.1 \mathrm{M}$ citric acid and $0.1 \mathrm{M}$ sodium citrate in distilled water. After cooling to room temperature, sections were washed twice in phosphate-buffered saline (PBS). Non-specific binding was blocked by incubating the sections with Ultra-V-Block (Lab Vision, Fremont, CA, USA) for $45 \mathrm{~min}$ at room temperature. Sections were then incubated at $4^{\circ} \mathrm{C}$ overnight with the inhibin- $\alpha$ mouse antibody (mouse IgG2a, clone R1; Serotec, Oxford, UK) at a dilution of 1:50 in Ultra-V-Block. After washing with PBS, sections were incubated with biotinylated secondary anti-mouse antibody (Vector Laboratories) for $30 \mathrm{~min}$ at room temperature. After incubation with the avidin-biotin peroxidase complex (diluted in $10 \mathrm{ml}$ PBS; Vector Laboratories) for $30 \mathrm{~min}$ and repeated washing steps with PBS, visualisation was performed with ABC substrate buffer (Vectastain Elite ABC kit; Vector Laboratories) and chromagen 3,3'-diaminobenzidine (DAB; Dako, Glostrup, Denmark) at a $1 \mathrm{mg} / \mathrm{ml}$ concentration for $4 \mathrm{~min}$. Sections were then counterstained with Mayer's acidic hematoxylin and dehydrated in an ascending series of alcohol (50-98\%). After xylol treatment, sections were mounted. Negative controls were performed by replacing the primary antibody with normal rabbit $\operatorname{IgG}$ as isotype control in the same dilution compared to the primary antibody, respectively. Immunohistochemical staining was performed using an appropriate positive control comprising ovaries containing follicular cysts $(16,26,27)$. Positive cells showed a brownish color and negative controls as well as unstained cells were blue.

Cells and cell culture. The cervical adenocarcinoma cell line HeLa (ATCC CCL2) and the cervical squamous carcinoma cell line CaSKi (ATCC CRL-1550) are ATCC-available cell lines (ATCC, LGC Promochem GmbH, Wesel, Germany). Cells were cultured in Quantum 263 medium (PAA, Pasching, Austria) supplemented with antibiotics at $37^{\circ} \mathrm{C}$ in a humidified atmosphere with $5 \% \mathrm{CO}_{2}$ as previously described $(9,15,23,28)$.
Immunofluorescence analysis. Immunofluorescence analysis was performed as previously described $(9,11-15,23,25)$. Briefly, cells grown on glass coverslips were fixed with acetone for $10 \mathrm{~min}$ at room temperature and washed twice with PBS. Non-specific binding was blocked by incubating the sections with Ultra-V-Block (Lab Vision) for $15 \mathrm{~min}$ at room temperature. Thereafter, slides were incubated with inhibin- $\alpha$ antibody (1:50 in dilution medium provided by Dako) overnight at $4^{\circ} \mathrm{C}$, followed by a 1:500 diluted Cy3-conjugated goat anti-mouse antibody (Dianova, Hamburg, Germany) for $30 \mathrm{~min}$ at room temperature. The slides were finally embedded in mounting buffer containing 4,6-diamino-2-phenylindole (DAPI) resulting in blue staining of the nuclei. Slides were embedded with Vectashield mounting medium (Axxora, Lörrach, Germany) and examined with a Zeiss (Jena, Germany) Axiophot photomicroscope. Digital images were obtained with a digital camera system (Axiocam, Zeiss) and saved on a computer system.

RT-PCR analysis. RNA was extracted from the cells using the Nucleospin RNA II kit (Macherey-Nagel, Düren, Germany). Reverse transcription was performed with M-MLV reverse transcriptase and oligo(dT) (Promega, Mannheim, Germany) as recommended by the supplier. PCR was performed in an Eppendorf Mastercycler with GoTaq (Promega) as previously described $(25,27)$. Primer sequences to amplify a 359-bp fragment of inhibin- $\alpha$ were in $5^{\prime}-3^{\prime}$ orientation: CCGGCCATCCCAGCATACACGC (forward primer) and GAGTTGAGCGTCGGGCTCTC (backward primer). $\beta$-actin primers were from Stratagene (The Netherlands). PCR cycling was performed after a 5 -min initiation at $94^{\circ} \mathrm{C}$ with 32 cycles of $1 \mathrm{~min}$ at $94^{\circ} \mathrm{C}, 1 \mathrm{~min}$ at $57^{\circ} \mathrm{C}, 2 \mathrm{~min}$ at $72^{\circ} \mathrm{C}$, followed by a 5-min extension at $72^{\circ} \mathrm{C}$.

\section{Results}

The inhibin- $\alpha$ subunit demonstrated no or minimal positive staining reaction in the normal and malignant cervical tissue (Fig. 1). Normal squamous epithelial cells demonstrated no or minimal reaction with the inhibin- $\alpha$ antibody, being primarily localised in mitotic cells (Fig. 1a). Squamous carcinomas also demonstrated no to minimal positive immunohistochemical staining reaction (Fig. 1b). Normal cervical glandular epithelium demonstrated also a minimal positive reaction primarily localised in the mitotic cells (Fig. 1c), while cervical adenocarcinomas showed no positive staining reaction (Fig. 1d). However, the immunoreactive reaction was albeit weak, inconsistent and mostly confined to mitotic cells in all analysed cervical tissues.

Cervical carcinoma cells are malignant cell lines derived from invasive cervical carcinomas of different origin. We therefore tested the expression of inhibin- $\alpha$ in the human cervical cancer cell lines HeLa and CaSKi. Immunofluorescence analysis of both cell lines expressed this $\alpha$-subunit at the protein level. Expression of inhibin- $\alpha$ was found to be located primarily in the cytoplasm (Fig. 2). However, since the expression of the inhibin- $\alpha$ was minimal in the HeLa cells, the CaSKi cell line might be a better model for further functional experiments regarding cervical pathogenesis.

To verify inhibin- $\alpha$ expression at the transcriptional level in human cervical cancer cells of different histological origin, 


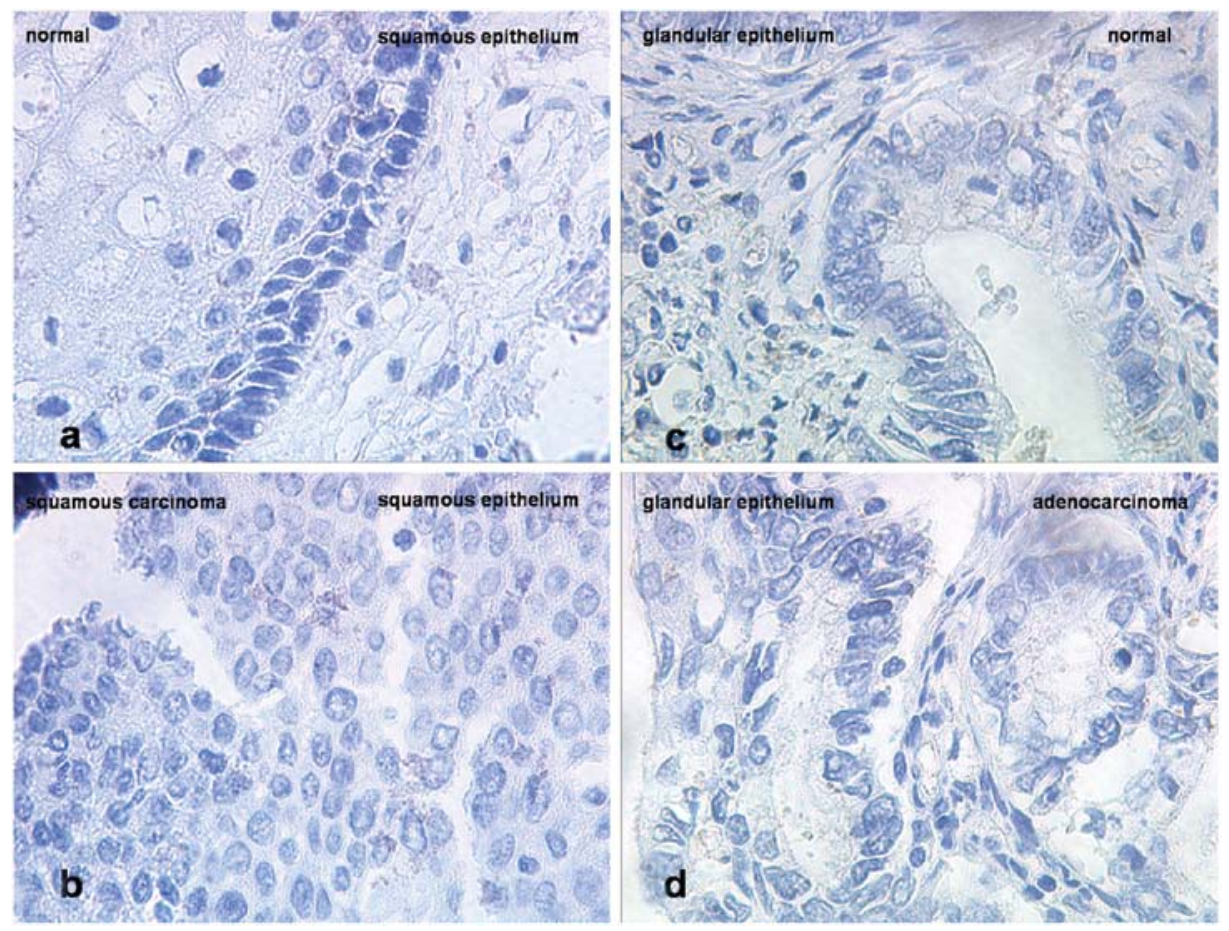

Figure 1. Immunohistochemical staining reaction of inhibin- $\alpha$ in normal and malignant cervical tissue. Normal squamous epithelial cells demonstrated no to minimal reaction with the inhibin- $\alpha$ antibody, being primarily positive in mitotic cells [(a), x400]. Squamous carcinomas also demonstrated no to minimal positive immunohistochemical staining reaction [(b), x400]. Normal cervical glandular epithelium demonstrated also a minimal positive reaction primarily localised in mitotic cells [(c), x400], while cervical adenocarcinomas showed no positive staining reaction [(d), x400]. However, the immunoreactive reaction was albeit weak and mostly confined to mitotic cells in all analysed cervical tissues.
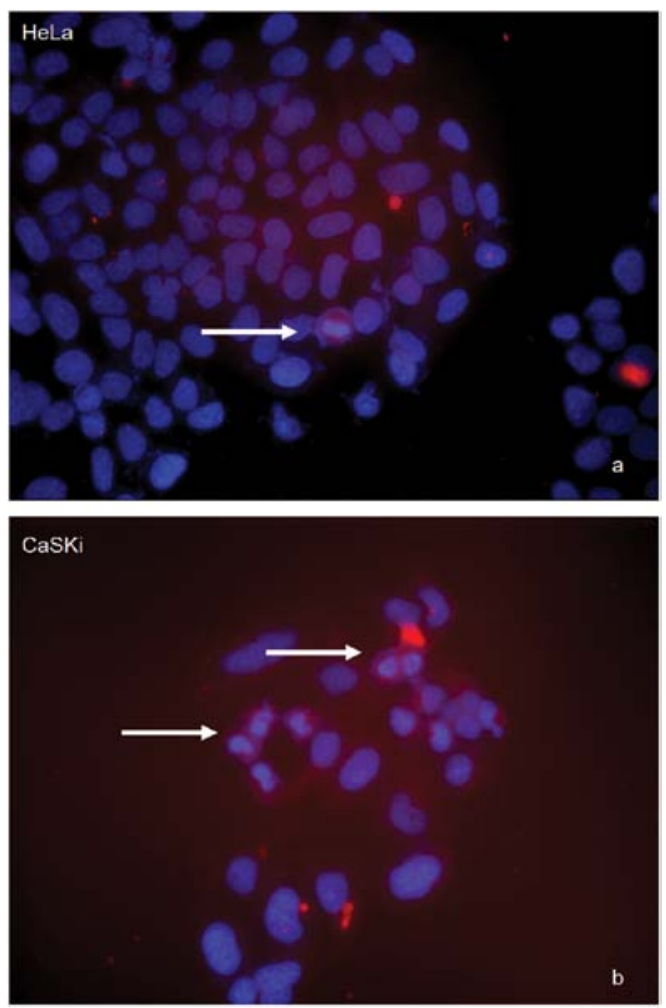

Figure 2. Localisation of inhibin- $\alpha$ expression in HeLa and CaSKi cells. The cervical carcinoma cell lines HeLa and CaSKi were analysed by immunofluorescence for the expression of inhibin- $\alpha$, showing a cytoplasmatic positive staining reaction in HeLa [(a), x400] and CaSKi [(b), x400] cells. However, the expression of inhibin- $\alpha$ was less intense in the HeLa cells compared to the CaSKi cells. Notably, the labelling intensity was stronger in mitotic cells of both cell lines (arrows).

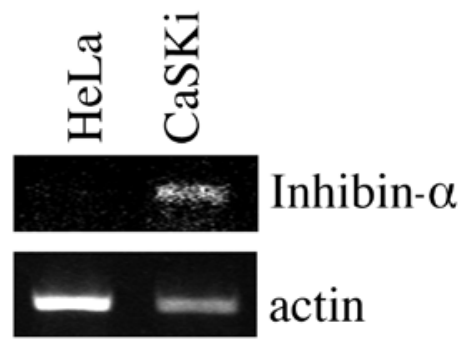

Figure 3. Inhibin- $\alpha$ expression in cervical carcinoma cell lines. HeLa and CaSKi cells were analysed by RT-PCR analysis for the expression of the inhibin- $\alpha$ subunit. Expression of $\beta$-actin was used as a control.

the squamous cervical cancer cell line CaSki and the cervical adenocarcinoma cell line HeLa were subjected to RT-PCR analysis for the expression of inhibin- $\alpha$ mRNA. Fig. 3 shows that this subunit is strongly expressed in CaSKi cells but poorly synthesised by HeLa cells. Therefore, the CaSKi cell line might be a better model for further functional experiments regarding cervical pathogenesis compared to the HeLa cell line.

\section{Discussion}

The inhibin/activin subunits have been detected in normal female reproductive tissue and endocrine tumours $(16,19,20,26,29)$. We demonstrated in this preliminary study for the first time the immunohistochemical expression of the inhibin- $\alpha$ subunit in normal and pathological human cervical tissue. Moreover, we observed the synthesis of this subunit also in cervical carcinoma 
cell lines of squamous and epithelial origins by using RNA amplification techniques. The putative expression of inhibin subunits in cervical cancer is of extreme importance, since activin signalling may be a promising target for therapeutic interventions $(30,31)$.

Notably, TGF- $\beta$ has been recognized as a tumour suppressor in premalignant stages of carcinogenesis with an additional dual role as a pro-oncogene in later stages of the disease, leading to metastasis $(19,32)$. Regarding metastasis, inhibition of TGF- $\beta$ suppresses experimental metastasis to multiple organs $(33,34)$. Inhibin A, inhibin B and activin A were detected in normal and malignant human uterine tissues, including cervical cancer (35), and the neoplastic transformation of the human cervix might also be related to dysregulation of TGF- $\beta$, leading to loss of cell cycle control (36).

However, the most important function is the tumoursuppressor activity of the $\alpha$-subunit (19), that was first identified after functional deletion of the inhibin- $\alpha$ gene in mice $(21,22)$. Meanwhile, loss of inhibin- $\alpha$ expression resulted in a poorer survival of endometrial cancer patients, suggesting a tumoursuppressor function in human endometrium (16). Additionally, a pro-tumourigenic and pro-metastatic function for inhibin- $\alpha$ in prostate cancer has been described (37). However, the exact molecular mechanism by which the inhibin- $\alpha$ subunit is implicated in carcinogenesis is still not clear.

In prostate cancer, the inhibin- $\alpha$ promoter can be silenced by hypermethylation $(38,39)$. Promoter hypermethylation, mostly described for cell cycle regulator proteins and E-cadherin expression, is a quite often observed gene silencing mechanism during human cancer progression (40). Furthermore, the inhibin- $\alpha$ subunit can be regulated by GATA and CCAAT/ enhancer-binding protein- $\beta$ transcription factors $(41,42)$, but too little is known about the involvement and expression of these transcription factors in human cervical carcinomas. However, generally it is believed that inhibin- $\alpha$ is a tumoursuppressor gene silenced by mechanisms common to other tumour-suppressor genes (43).

The loss of the inhibin- $\alpha$ subunit production in mice resulted in a marked increase in activin production in the ovary. The inhibin- $\alpha$ sufficient mice presented with cachectic symptoms that were associated with the compensatory excessive secretion of activin (22). Additionally, inhibin resistance with a subsequent increased activin function may contribute to the aggressive behaviour of ovarian cancer cells in vitro (44). Inhibin- $\beta A$ is overexpressed in lung adenocarcinomas and this overexpression is associated with a poorer survival, probably affecting promoter methylation and histone acetylation (45). Notably, an overexpression of activin A in esophageal squamous cell carcinoma resulted in a worse overall prognosis (46), probably leading to cell growth promotion, tumourigenicity, invasion and resistance to apoptosis in these squamous cancer cells (47). However, whether the inhibin subunits have similar functions in cervical pathogenesis and carcinogenesis remains unclear.

In conclusion, we demonstrated an expression of the inhibin- $\alpha$ subunit in normal and malignant cervical tissue, as well as cervical cancer cells. However, the immunoreactive reaction was albeit weak and mostly confined to mitotic cells in all analysed cervical tissues. Additionally, the expression pattern of this subunit was rather inconsistent. Therefore, the immunohistochemical evaluation of this subunit in cervical tissue cannot be used as a prognostic marker as suggested for endometrial cancer $(16,18,25)$.

Although the physiological role is still quite unclear in cervical tissue, inhibin- $\alpha$ may play important roles in carcinogenesis. Moreover, the synthesis of this subunit in cervical carcinoma cell lines of squamous and epithelial origins allows the use of these cell lines in elucidating its functions in cervical pathogenesis and carcinogenesis. However, since the expression of the inhibin- $\alpha$ is minimal in HeLa cells, as assessed by immunofluorescence and RT-PCR, the CaSKi cell line may be a better model for further functional experiments regarding cervical pathogenesis.

\section{Acknowledgements}

We would like to thank Mrs. C. Kuhn, Mrs. S. Kunze, Mrs. S. Schulze and Mrs. I. Wiest for their excellent work with the cervical tissue samples. Moreover, we express our gratitude to Dr U. Jeschke and Dr A. Brüning for their help in this study. This study was partially supported by the FöFoLe program of the Ludwig Maximilian University of Munich (297/03), the Friedrich Baur Institute of Munich and the Weigland Stipendium Program of the Ludwig Maximilian University of Munich.I.M. is supported by the German Research Foundation (Deutsche Forschungsgemeinschaft, DFG BR 3641/3-1).

\section{References}

1. Franco EL, Schlecht NF and Saslow D: The epidemiology of cervical cancer. Cancer J 9: 348-359, 2003.

2. Waggoner SE: Cervical cancer. Lancet 361: 2217-2225, 2003.

3. Munoz N, Bosch FX, De Sanjose S, et al: Epidemiologic classification of human papillomavirus types associated with cervical cancer. N Engl J Med 348: 518-527, 2003.

4. Zur Hausen H: Papillomaviruses in the causation of human cancers - a brief historical account. Virology 384: 260-265, 2009.

5. Barthell E, Woelber L, Hellner K, et al: Baseline characteristics and prevalence of HPV $6,11,16,18$ in young German women participating in phase III clinical trials of a quadrivalent HPV (6/11/16/18) vaccine. Arch Gynecol Obstet 279: 803-807, 2009.

6. Menczer J, Kogan L, Schejter E, Liphshiz I and Barchana M: A population-based study of selected demographic characteristics of Israeli-Jewish women with cervical squamous cell carcinoma. Arch Gynecol Obstet 283: 629-633, 2011.

7. Xia Y and Schneyer AL: The biology of activin: recent advances in structure, regulation and function. J Endocrinol 202: 1-12, 2009.

8. De Kretser DM, Hedger MP, Loveland KL and Phillips DJ: Inhibins, activins and follistatin in reproduction. Hum Reprod Update 8: 529-541, 2002.

9. Bergauer F, Bruning A, Shabani N, et al: Inhibin/activin-betaE subunit in normal and malignant human cervical tissue and cervical cancer cell lines. J Mol Histol 40: 353-359, 2009.

10. Kimmich T, Bruning A, Kaufl SD, et al: Inhibin/activin-betaC and -betaE subunits in the Ishikawa human endometrial adenocarcinoma cell line. Arch Gynecol Obstet 282: 185-191, 2010.

11. Käufl SD, Kuhn C, Kunze S, et al: Inhibin/activin-betaC subunit does not represent a prognostic parameter in human endometrial cancer. Arch Gynecol Obstet 284: 199-207, 2011.

12. Käufl SD, Makovitzky J, Kuhn C, Kunze S, Jeschke U and Mylonas I: Inhibin/activin-betaC subunit in human endometrial adenocarcinomas and HEC-1a adenocarcinoma cell line. In Vivo 24: 695-698, 2010.

13. Gingelmaier A, Bruning A, Kimmich T, et al: Inhibin/activinbetaE subunit is expressed in normal and pathological human placental tissue including chorionic carcinoma cell lines. Arch Gynecol Obstet 283: 223-230, 2011.

14. Weissenbacher T, Bruning A, Kimmich T, Makovitzky J, Gingelmaier A and Mylonas I: Immunohistochemical labeling of the inhibin/activin betaC subunit in normal human placental tissue and chorionic carcinoma cell lines. J Histochem Cytochem 58: 751-757, 2010. 
15. Blankenstein T, Jückstock J, Shabani N, et al: Immunolabelling of the inhibin/activin-betaC subunit in normal and malignant human uterine cervical tissue and cervical cancer cell lines. Oncol Rep 25: 147-152, 2011

16. Mylonas I, Worbs S, Shabani N, et al: Inhibin-alpha subunit is an independent prognostic parameter in human endometrial carcinomas: analysis of inhibin/activin-alpha, -betaA and -betaB subunits in 302 cases. Eur J Cancer 45: 1304-1314, 2009.

17. Mylonas I: Inhibin-alpha, -betaA and -betaB subunits in uterine non-endometrioid carcinomas: prognostic significance and clinical implications. Eur J Cancer 46: 2485-2493, 2010.

18. Worbs S, Shabani N, Mayr D, et al: Expression of the inhibin/ activin subunits (-alpha, -betaA and -betaB) in normal and carcinogenic endometrial tissue: possible immunohistochemical differentiation markers. Oncol Rep 17: 97-104, 2007.

19. Stenvers KL and Findlay JK: Inhibins: from reproductive hormones to tumor suppressors. Trends Endocrinol Metab 21: 174-180, 2010

20. Risbridger GP, Schmitt JF and Robertson DM: Activins and inhibins in endocrine and other tumors. Endocr Rev 22: 836-858, 2001.

21. Matzuk MM, Finegold MJ, Su JG, Hsueh AJ and Bradley A: Alpha-inhibin is a tumour-suppressor gene with gonadal specificity in mice. Nature 360: 313-319, 1992.

22. Matzuk MM, Finegold MJ, Mather JP, Krummen L, Lu H and Bradley A: Development of cancer cachexia-like syndrome and adrenal tumors in inhibin-deficient mice. Proc Natl Acad Sci USA 91: 8817-8821, 1994.

23. Jückstock K, Brüning A, Blankenstein T, et al: Immunolabelling of the inhibin-betaA and -betaB subunit in normal and malignan human cervical tissue and cervical cancer cell line. Int J Gynecol Cancer 20: 1177-1125, 2010.

24. Burges A, Shabani N, Bruning A and Mylonas I: Inhibin-betaA and -betaB subunits in normal and malignant glandular epithelium of uterine cervix and HeLa cervical cancer cell line. Arch Gynecol Obstet 281: 511-517, 2010.

25. Mylonas I: Inhibin-alpha subunit expression in uterine endometrioid adenocarcinomas and endometrial cancer cell lines: a potential prognostic factor. Int J Mol Med 27: 309-318, 2011.

26. Mylonas I, Jeschke U, Wiest I, et al: Inhibin/activin subunits alpha, beta-A and beta-B are differentially expressed in normal human endometrium throughout the menstrual cycle. Histochem Cell Biol 122: 461-471, 2004.

27. Mylonas I, Bruning A, Shabani N, Kunze S and Kupka MS Evidence of inhibin/activin subunit betaC and betaE synthesis in normal human endometrial tissue. Reprod Biol Endocrinol 8: 143, 2010.

28. Bruning A, Makovitzky J, Gingelmaier A, Friese K and Mylonas I The metastasis-associated genes MTA1 and MTA3 are abundantly expressed in human placenta and chorionic carcinoma cells. Histochem Cell Biol 132: 33-38, 2009.

29. Mylonas I, Jeschke U, Shabani N, Kuhn C, Friese K and Gerber B: Inhibin/activin subunits (inhibin-alpha, -betaA and -betaB) are differentially expressed in human breast cancer and their metastasis. Oncol Rep 13: 81-88, 2005.

30. Zhou X, Wang JL, Lu J, et al: Reversal of cancer cachexia and muscle wasting by ActRIIB antagonism leads to prolonged survival. Cell 142: 531-543, 2010.

31. Tsuchida K, Nakatani M, Hitachi K, et al: Activin signaling as an emerging target for therapeutic interventions. Cell Commun Signal 7: 15, 2009
32. Risbridger GP, Ball EM, Wang H, Mellor SL and Peehl DM Re-evaluation of inhibin alpha subunit as a tumour suppressor in prostate cancer. Mol Cell Endocrinol 225: 73-76, 2004.

33. Ehata S, Hanyu A, Fujime M, et al: Ki26894, a novel transforming growth factor-beta type I receptor kinase inhibitor, inhibits in vitro invasion and in vivo bone metastasis of a human breast cancer cell line. Cancer Sci 98: 127-133, 2007.

34. Ogino H, Yano S, Kakiuchi S, et al: Follistatin suppresses the production of experimental multiple-organ metastasis by small cell lung cancer cells in natural killer cell-depleted SCID mice. Clin Cancer Res 14: 660-667, 2008.

35. Petraglia F, Florio P, Luisi S, et al: Expression and secretion of inhibin and activin in normal and neoplastic uterine tissues. High levels of serum activin A in women with endometrial and cervical carcinoma. J Clin Endocrinol Metab 83: 1194-1200, 1998.

36. Farley J, Gray K, Nycum L, Prentice M, Birrer MJ and Jakowlew SB: Endocervical cancer is associated with an increase in the ligands and receptors for transforming growth factor-beta and a contrasting decrease in p27(Kip1). Gynecol Oncol 78: 113-122, 2000

37. Balanathan $\mathrm{P}$, Williams ED, Wang $\mathrm{H}$, et al: Elevated level of inhibin-alpha subunit is pro-tumourigenic and pro-metastatic and associated with extracapsular spread in advanced prostate cancer. Br J Cancer 100: 1784-1793, 2009.

38. Balanathan P, Ball EM, Wang H, Harris SE, Shelling AN and Risbridger GP: Epigenetic regulation of inhibin alpha-subunit gene in prostate cancer cell lines. J Mol Endocrinol 32: 55-67, 2004.

39. Schmitt JF, Millar DS, Pedersen JS, et al: Hypermethylation of the inhibin alpha-subunit gene in prostate carcinoma. Mol Endocrinol 16: 213-220, 2002.

40. Jiang SW, Li J, Podratz K and Dowdy S: Application of DNA methylation biomarkers for endometrial cancer management. Expert Rev Mol Diagn 8: 607-616, 2008.

41. Robert NM, Miyamoto Y, Taniguchi H and Viger RS: LRH-1/ NR5A2 cooperates with GATA factors to regulate inhibin alphasubunit promoter activity. Mol Cell Endocrinol 257-258: 65-74, 2006.

42. Burkart AD, Mukherjee A, Sterneck E, Johnson PF and Mayo KE: Repression of the inhibin alpha-subunit gene by the transcription factor CCAAT/enhancer-binding protein-beta. Endocrinology 146: 1909-1921, 2005

43. Ball EM, Mellor SL and Risbridger GP: Cancer progression: is inhibin alpha from Venus or Mars? Cytokine Growth Factor Rev 15: 291-296, 2004.

44. Steller MD, Shaw TJ, Vanderhyden BC and Ethier JF: Inhibin resistance is associated with aggressive tumorigenicity of ovarian cancer cells. Mol Cancer Res 3: 50-61, 2005.

45. Seder CW, Hartojo W, Lin L, et al: Upregulated INHBA expression may promote cell proliferation and is associated with poor survival in lung adenocarcinoma. Neoplasia 11: 388-396, 2009.

46. Yoshinaga K, Mimori K, Yamashita K, Utsunomiya T, Inoue $H$ and Mori M: Clinical significance of the expression of activin A in esophageal carcinoma. Int J Oncol 22: 75-80, 2003.

47. Yoshinaga K, Yamashita K, Mimori K, Tanaka F, Inoue H and Mori M: Activin a causes cancer cell aggressiveness in esophageal squamous cell carcinoma cells. Ann Surg Oncol 15: 96-103, 2008 . 